\title{
Inputs Underlying the ON-OFF Light Responses of Type 2 Wide-Field Amacrine Cells in TH::GFP Mice
}

\author{
Gabriel C. Knop, Andreas Feigenspan, Reto Weiler, and Karin Dedek \\ Department of Neurobiology, University of Oldenburg, 26111 Oldenburg, Germany
}

In the mammalian retina, two types of catecholaminergic amacrine cells have been described. Although dopaminergic type 1 cells are well characterized, the physiology of type 2 cells is, so far, unknown. To target type 2 cells specifically, we used a transgenic mouse line that expresses green fluorescent protein under the control of the tyrosine hydroxylase promoter. Type 2 cells are GABAergic and have an extensive dendritic arbor, which stratifies in the middle of the inner plexiform layer. Our data suggest that type 2 cells comprise two subpopulations with identical physiological properties: one has its somata located in the inner nuclear layer and the other in the ganglion cell layer. Immunostaining with bipolar cell markers suggested that type 2 cells receive excitatory inputs from type 3 OFF and type 5 ON bipolar cells. Consistently, patch-clamp recordings showed that type 2 cells are ON-OFF amacrine cells. Blocking excitatory inputs revealed that different rod and cone pathways are active under scotopic and mesopic light conditions. Blockade of inhibitory inputs led to membrane potential oscillations in type 2 cells, suggesting that GABAergic and glycinergic amacrine cells strongly influence type 2 cell signaling. Among the glycinergic amacrine cells, we identified the VGluT3-immunoreactive amacrine cell as a likely candidate. Collectively, light responses of type 2 cells were remarkably uniform over a wide range of light intensities. These properties point toward a general function of type 2 cells that is maintained under scotopic and mesopic conditions.

\section{Introduction}

The mammalian retina contains more than 30 different types of amacrine cells (MacNeil and Masland, 1998; Badea and Nathans, 2004), which presumably each exert unique functions. Amacrine cells receive inputs from bipolar cells, other amacrine cells, and/or ganglion cells. Amacrine cell outputs include feedback inhibition to bipolar cells (Flores-Herr et al., 2001; Molnar and Werblin, 2007), feedforward inhibition to ganglion cells (Cook and McReynolds, 1998; Roska and Werblin, 2001), and (serial) inhibition to other amacrine cells (Hsueh et al., 2008; Eggers and Lukasiewicz, 2010).

Amacrine cells can be divided into different groups according to their dendritic tree size. Narrow-field amacrine cells possess small dendritic arbors $(<200 \mu \mathrm{m})$, are glycinergic (Menger et al., 1998), and mediate local interactions, often across the ON and OFF sublaminae of the inner plexiform layer (IPL) (Hsueh et al., 2008). Medium-field and wide-field amacrine (WFA) cells exhibit large dendritic arbors (up to $1 \mathrm{~mm}$ ). These cells are GABAergic and comprise $\sim 20$ subtypes (Badea and Nathans, 2004; Lin

Received Nov. 30, 2010; revised Feb. 3, 2011; accepted Feb. 4, 2011.

Author contributions: G.C.K., A.F., R.W., and K.D. designed research; G.C.K., A.F., and K.D. performed research; G.C.K., A.F., and K.D. analyzed data; G.C.K., A.F., and K.D. wrote the paper.

This work was supported by the Deutsche Forschungsgemeinschaft (WE 849/16-1/2 to K.D. and R.W.). We thank Susanne Wallenstein and Bettina Kewitz for excellent technical assistance and Jennifer Trümpler for reading and improving the manuscript. We also thank Thomas Euler for the light stimulation software QDS, Francoise Haeseleer and Silke Haverkamp for the generous gifts of the anti-CaB5 and anti-VGluT3 antibodies, respectively.

Correspondence should be addressed to Dr. Karin Dedek, University of Oldenburg, Department of Neurobiology, P. 0. Box 2503, D-26111 Oldenburg, Germany. E-mail: karin.dedek@uni-oldenburg.de.

G. C. Knop's and A. Feigenspan's present address: Department of Biology, Animal Physiology, University of Erlangen, 91054 Erlangen, Germany.

DOI:10.1523/JNEUROSCI.6235-10.2011

Copyright $\odot 2011$ the authors $\quad 0270-6474 / 11 / 314780-12 \$ 15.00 / 0$ and Masland, 2006; Pérez De Sevilla Müller et al., 2007; Dedek et al., 2009; Majumdar et al., 2009). WFA cells either mediate lateral interactions, which are often confined to a single stratum in the IPL (Hsueh et al., 2008), or provide local reciprocal inhibition, as was recently shown for A17 cells (Grimes et al., 2010). Though it is well known that WFA cells are involved in spatiotemporal processing, such as surround inhibition (Lukasiewicz, 2005) or contrast adaptation (Demb, 2008), the connectivity and functional properties of most amacrine cells are largely unknown.

Apart from GABA, WFA cells often release a second neurotransmitter, such as catecholamines or neuropeptides. In the mammalian retina, two types of catecholaminergic amacrine cells have been described (Versaux-Botteri et al., 1986; Mariani and Hokoc, 1988; Zhang et al., 2004): type 1 cells, which are dopaminergic (DA cells); and type 2 cells, which are presumably adrenergic (Versaux-Botteri et al., 1986). DA cells are interplexiform cells and play a major role in retinal light adaptation (Witkovsky, 2004). Recently, DA cells have been shown to receive inputs via en passant synapses from ON bipolar cells (Dumitrescu et al., 2009; Hoshi et al., 2009) and via a centrifugal pathway from melanopsinexpressing ganglion cells (Zhang et al., 2008). In contrast, inputs to type 2 cells have only been described on the ultrastructural level in the monkey retina (Mariani, 1991). To analyze type 2 cells, we used a transgenic mouse line that expresses the green fluorescent protein (GFP) under the tyrosine hydroxylase (TH) promoter (TH::GFP mouse). Using a mouse line expressing a red fluorescent protein under a similar promoter, Zhang et al. (2004) described the morphology and retinotopic density of type 2 cells in the mouse retina but did not analyze their physiology. Here, we used immunohistochemistry and patch-clamp recordings to analyze the response and receptive field properties of type 2 cells and 
Table 1. Primary antibodies used in this study

\begin{tabular}{llll}
\hline Antibody & Immunogen & Source & Dilution, species, type \\
\hline Calret & Guinea pig calretinin, full-length amino acid sequence & Millipore, No. AB1550 & $1: 500$, goat, polyclonal \\
CaB5 & Recombinant ms CaB5 & F. Haeseleer, Department of Ophthalmology, University of Washington, Seattle, WA & $1: 1000$, rabbit, polyclonal \\
CtBP2 & Mouse C-terminal binding protein 2, amino acids 361-445 & BD Biosciences, No. 612044 & $1: 5000$, mouse, monoclonal \\
GABA & GABA coupled to bovine serum albumine & Sigma, No. A-2052 & $1: 2000$, rabbit, polyclonal \\
GlyR $\alpha 2$ & N-terminal 18 residues of the human GlyR $\alpha 2$ subunit & Santa Cruz Biotechnology, sc-17279 & $1: 300$, goat, polyclonal \\
TH & Epitope in the mid-portion of the TH molecule & ImmunoStar, 22941 & $1: 500$, mouse, monoclonal \\
VGluT1 & Amino acids 542-560 of rat VGlut1 & Millipore, AB5905 & $1: 10,000$, guinea pig, polyclonal \\
VGluT3 & Synthetic peptide from rat VGluT3 protein & Millipore, AB5421 & $1: 5000$, guinea pig, polyclonal \\
\hline
\end{tabular}

present, to our knowledge, the first characterization of excitatory and inhibitory inputs to type 2 cells.

\section{Materials and Methods}

Unless stated otherwise, all chemicals were purchased from Roth.

Animals and tissue preparation. A transgenic mouse line that expressed GFP under control of the TH promoter on a C57BL/6J genetic background (Matsushita et al., 2002) was used. Mice were housed under a $12 \mathrm{~h}$ light/dark cycle. All experiments were performed in accordance with the institutional guidelines for animal welfare and the laws on animal experimentation issued by the German government. Before patch-clamp recordings, mice were dark-adapted between $3 \mathrm{~h}$ and overnight. Animals were deeply anesthetized with $\mathrm{CO}_{2}$ and killed by cervical dislocation. Eyes were enucleated and transferred to a dish with carboxygenated (95\% $\mathrm{O}_{2} / 5 \% \mathrm{CO}_{2}$ ) Ames' medium ( $\mathrm{pH} 7.4$; Sigma) or, for patch-clamp recordings, carboxygenated extracellular solution (in mM: $125 \mathrm{NaCl}, 2.5 \mathrm{KCl}, 1$ $\mathrm{CaCl}_{2}, 1.6 \mathrm{MgCl}_{2}, 25 \mathrm{NaHCO}_{3}, 10$ glucose, $\mathrm{pH} 7.4$ ) at room temperature. Eyes were opened and cornea, lens, and vitreous were removed, leaving the retina in the posterior eyecup.

Immunohistochemistry. Immunohistochemistry was performed as described previously (Dedek et al., 2009). Briefly, the posterior eyecup was fixed for $15-30 \mathrm{~min}$ in $2-4 \%$ paraformaldehyde in $0.1 \mathrm{~m}$ phosphate buffer (PB, pH 7.4). After fixation, eyecups were cryoprotected in $30 \%$ sucrose in $0.1 \mathrm{M} \mathrm{PB}$ overnight. Vertical cryosections $(18 \mu \mathrm{m})$ were cut and blocked with $5 \%$ chemiblocker (Millipore Bioscience Research Reagents) in $0.1 \mathrm{M}$ PB plus $0.5 \%$ Triton $\mathrm{X}-100$ pkus $0.05 \% \mathrm{NaN}_{3}$ or with normal goat or donkey serum in PB plus $0.5 \%$ Triton X-100 for $1 \mathrm{~h}$ at room temperature. The intense GFP signal of the transgenic animals was visible without immunostaining and did not need to be enhanced. Sections were incubated with the primary antibodies listed in Table 1 in the same solutions which were used for blocking. After incubation at $4^{\circ} \mathrm{C}$ overnight and three washes in $0.1 \mathrm{M} \mathrm{PB}$, secondary antibodies conjugated to Alexa Fluor 488, Alexa Fluor 568 (Invitrogen), Cy3, or Cy5 (Jackson Immunoresearch) were applied at room temperature for $2 \mathrm{~h}$. Secondary antibodies were diluted 1:500 in 5\% chemiblocker in $0.1 \mathrm{M} \mathrm{PB}$ plus $0.5 \%$ Triton X-100 plus $0.05 \% \mathrm{NaN}_{3}$ or in $1 \%$ serum in $0.1 \mathrm{M} \mathrm{PB}$ plus $0.5 \%$ Triton X-100. Finally, sections were rinsed extensively in $0.1 \mathrm{M} \mathrm{PB}$ and mounted in Vectashield (Vector Laboratories). For controls, the primary antibody was omitted; occasional unspecific labeling of blood vessels was observed for the secondary donkey-anti-mouse Alexa Fluor 568 antibody. Retina whole-mounts were incubated for $5 \mathrm{~d}$ in the primary and $3 \mathrm{~d}$ in the secondary antibody solutions.

Patch-clamp recordings. For patch-clamp recordings, tissue dissection was performed either in dim red light or using night-vision goggles. The retina was isolated from the pigment epithelium and stored in extracellular solution at room temperature. Before recording, the retinal wholemount was transferred to a small chamber (volume, $\sim 1 \mathrm{ml}$ ) and continuously superfused with carboxygenated, heated, extracellular solution $\left(35^{\circ} \mathrm{C}, 5 \mathrm{ml} / \mathrm{min}\right)$. A nylon grid was used to flatten the retina. The recording chamber was placed under an upright laser scanning microscope (Leica DM-LFS) equipped with an infrared laser tuned to 850-870 nm (Tsunami Ti:sapphire; Spectra Physics). Using two-photon excitation, GFP-expressing cells were visualized and targeted. Whole-cell patch-clamp recordings were performed to measure light responses from type 2 cells. Glass pipettes $(\sim 5 \mathrm{M} \Omega)$ were made from borosilicate capillaries (Hilgenberg) with a P-97 electrode puller (Sutter Instruments). All recordings were done in current-clamp mode using a SEC-05LX amplifier (NPI Electronics). Intracellular solution contained the following (in mM): $125 \mathrm{~K}$-gluconate, $10 \mathrm{KCl}, 0.5$ EGTA, 10 HEPES, titrated to $\mathrm{pH} 7.4$ with $\mathrm{KOH}$. In initial recordings, $100 \mu \mathrm{M}$ Alexa Fluor594 (Invitrogen) was added to visualize cell morphology and control for cell identity. In some experiments, $100 \mu \mathrm{M} \mathrm{L}-\mathrm{AP} 4$ and/or $100 \mu \mathrm{M}$ CNQX (both for Ascent Scientific) were added to the extracellular solution to block metabotropic and/or ionotropic non-NMDA glutamate receptors, respectively. In another set of experiments, $1-2 \mu \mathrm{M}$ strychnine or $100 \mu \mathrm{M}$ bicuculline were added to block glycinergic or $\mathrm{GABA}_{\mathrm{A}}$-mediated transmission, respectively.

Light stimulation. Visual stimuli were presented via a computercontrolled CRT monitor using QDS 2.0 stimulation software (Thomas Euler, University of Tübingen, Tübingen, Germany). The monitor image was projected through the condenser of the microscope and focused on the level of the photoreceptors on the bottom of the recording chamber. Monitor spectrum and intensity were measured with a spectrometer (USB4000; Ocean Optics) and yielded a maximum photometric luminance of $30 \mathrm{~lx}$, which is in the mesopic range. Following optical conversion standards and assuming an effective rod cross section of $0.67 \mu \mathrm{m}$ (Lyubarsky et al., 2004), this luminance was calculated to produce $3 \times$ $10^{4}$ photoisomerizations per rod per second. A set of calibrated neutral density filters (ITOS) was used to attenuate light stimuli up to $5.8 \mathrm{log}$ units, close to the absolute visual threshold.

The light stimulus consisted of white light spots and annular stimuli centered on the soma of the recorded cell. Stimuli were presented without background for $3 \mathrm{~s}$ to discern $\mathrm{ON}$ and OFF light responses. Each stimulus presentation was followed by a $15 \mathrm{~s}$ pause to keep adaptation to a minimum. For area summation measurements, spots with diameters from $50 \mu \mathrm{m}$ to the full stimulation area $(1000 \mu \mathrm{m})$ were projected. In general, high-contrast ( $>95 \%$ Michelson) stimuli were applied. For pharmacological experiments, a constant background illumination (0.6 $\mathrm{Rh}^{\star} / \mathrm{rod} / \mathrm{s}$ for low/high scotopic, $600 \mathrm{Rh}^{\star} / \mathrm{rod} / \mathrm{s}$ for mesopic conditions) was presented for at least $1 \mathrm{~min}$ before measurements and maintained during drug wash-in and wash-out to generate different adaptational conditions.

Data acquisition and analysis. Data acquisition was done with a BNC2090 D/A converter (National Instruments) and WinWCP software (John Dempster, Strathclyde University, Glasgow, UK). Data were sampled at $10 \mathrm{kHz}$, low-pass filtered at $3-5 \mathrm{kHz}$, and evaluated offline using WinWCP. All electrophysiological data were averaged from three trials. To quantify light responses, positive deviations in membrane potential were integrated over the time of stimulus presentation $(3 \mathrm{~s}$, ON responses) or $3 \mathrm{~s}$ immediately after stimulus presentation (OFF responses). To account for cell-specific differences, ON and OFF depolarizations of each cell were normalized to the cell's largest light response. Additionally, maximum depolarization was determined and time to peak of the early, transient depolarization was analyzed by determining the time from stimulus onset or offset to maximum depolarization, respectively.

Intracellular dye injections. To reveal the morphology of GFPexpressing cells and check for gap junctional coupling, injections of fluorescent dye and neuronal tracers were performed. Retinal wholemounts were prepared as described above and mounted on filter paper. GFP-expressing cell bodies were injected under visual control with sharp microelectrodes (70-120 M $\Omega$ ) made of borosilicate glass (Hilgenberg). A mixture of 10 mm Alexa Fluor 594 (Invitrogen) and 3\% Neurobiotin 
(Axxora), diluted in $100 \mathrm{~mm} \mathrm{KCl}$, was iontophoresed with pulsed current (0.25-1 nA) for 3-6 min. After injection, the tracer was allowed to diffuse for at least $30 \mathrm{~min}$ before tissue fixation ( $30 \mathrm{~min}, 4 \%$ paraformaldehyde). Then, whole-mounts were washed in PB, blocked with $5 \%$ chemiblocker, and incubated with streptavidin-Cy3 (1:400; Dianova) for $3 \mathrm{~d}$. After three final washes in $\mathrm{PB}$, tissue was mounted with Vectashield and stored at $4^{\circ} \mathrm{C}$ in the dark.

Image acquisition and analyses. Sections and whole-mounts were examined with a Leica TCS SL confocal microscope with $40 \times($ NA 1.25) or $63 \times($ NA 1.32) oil-immersion objectives. Scanning was performed sequentially to rule out cross talk between channels (laser lines: $488 \mathrm{~nm}$, $543 \mathrm{~nm}, 633 \mathrm{~nm}$ ) at $1024 \times 1024$ pixel resolution. Brightness and contrast of the final images were adjusted in Adobe Photoshop 7.0 or ImageJ (http://rsbweb.nih.gov/ij/). Unless stated otherwise, maximum projections of collapsed confocal stacks are shown.

To evaluate bipolar cell inputs to type 2 cells, confocal stacks were analyzed using Image and the plug-ins colocalization highlighter, color profiler, and point picker. First, we looked for staining with the synaptic ribbon marker that was in close vicinity to the type 2 cell dendrite. If the synaptic marker is truly associated with the type 2 cell dendrite, it should rotate with the dendrite. This was checked visually by rotating confocal stacks around the $x$-axis (data not shown). Synaptic markers truly associated with the type 2 cell terminal were counted using the point picker plug-in. To control whether these synaptic ribbons were also colocalized with the bipolar cell marker, we manually performed an object-based colocalization analysis (Bolte and Cordelières, 2006). Straight lines were placed through the center of putative synapses in single confocal scans. However, mispositioning of the vector may have led to underestimation of colocalization events (Bolte and Cordelières, 2006). The color profiler plug-in was used to calculate the pixel intensity along this straight line. If the pixel intensity in the channels for the bipolar cell marker and the synaptic marker was larger than a defined threshold (threshold 50 with values between 0 and 255), we normalized pixel intensity and defined colocalization between the bipolar cell marker and the synaptic marker as when the true overlap distance of the normalized fluorescence intensity curves at mid-height was larger than the resolution of the objective used for image acquisition ( $63 \times \mathrm{NA} 1.32: \sim 245 \mathrm{~nm}$ lateral resolution at 530 $\mathrm{nm}$ ) (Bolte and Cordelières, 2006). In that case, we marked the synaptic structure, again using the point picker plug-in. If the threshold was not reached or the true overlap distance was smaller than the lateral resolution of the microscope objective, the ribbon synapse most likely originated from another cell and was marked differently. In this way, we obtained quantitative estimates for inputs from bipolar cells and glycinergic amacrine cells to type 2 cells.

To determine the density of type 2 cells, six retinal fields $(500 \times 500$ $\mu \mathrm{m})$ from three whole-mount retinas were analyzed using the $20 \times(\mathrm{NA}$ $0.5)$ objective. Staining for TH was used to visualize DA cells. To obtain the number of type 2 cells, we counted GFP-positive but TH-negative cells in the inner nuclear layer (INL) and ganglion cell layer (GCL) (Zhang et al., 2004; Contini et al., 2010). Dendritic field size was determined by fitting an ellipse to a convex polygon that connects the dendritic tips of dye-filled cells.

\section{Results}

GFP-positive cells comprise two populations of WFA cells

A transgenic mouse line that expresses GFP under control of the TH promoter (Matsushita et al., 2002) was generated. Vertical retina sections from TH::GFP mice showed two distinct populations of GFP-positive cells (Fig. 1). One population had large oval somata (diameter, $10.8 \pm 1.6 \mu \mathrm{m} ; n=17$ ), which were located in the proximal INL. These cells stratified in layer S1 of the IPL (Fig. $1 A$, arrow). We regularly observed interplexiform dendrites ascending from layer S1 toward the outer plexiform layer (data not shown). This suggests that this population of GFP-positive cells corresponds to DA type 1 cells (Versaux-Botteri et al., 1986; Gustincich et al., 1997). Staining TH::GFP retinas with an antibody against TH confirmed this: GFP-positive cells with large somata were $\mathrm{TH}$-immunoreactive (Fig. $1 \mathrm{~B}$ ), as described previ-
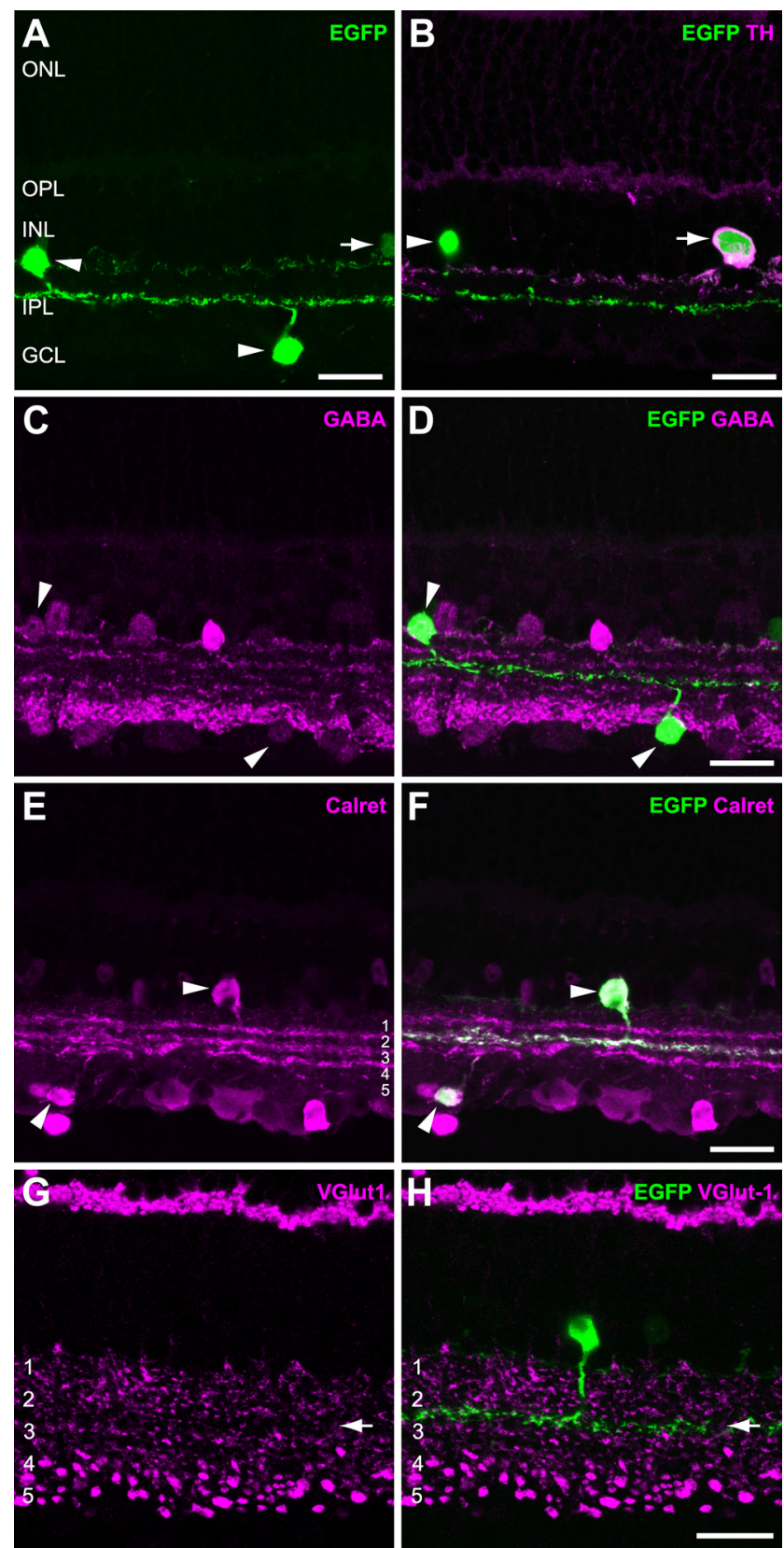

Figure 1. Type 2 cells express GFP, are GABAergic, and stratify between layers $\$ 2$ and $S 3$ of the IPL $A-F$, Projections of image stacks of vertical retina sections from a TH::GFP mouse labeled with antibodies against TH $(\boldsymbol{B}), \mathrm{GABA}(\boldsymbol{C}, \boldsymbol{D})$, calretinin $(\boldsymbol{E}, \boldsymbol{F})$, and VGlut- $1(\boldsymbol{G}, \boldsymbol{H}) . \boldsymbol{A}$, GFP expression in TH::GFP mice is confined to two different populations of amacrine cells. Arrow, DA cell, which stratifies in layer S1 of the IPL. Arrowheads, Two type 2 cells, one with its soma in the INL and one with its soma in the GCL. B, Different cryosection than in $\boldsymbol{A}$. Type 2 cells (arrowhead) are not labeled with TH antibodies, whereas a DA cell is clearly labeled (arrow). C, D, GFP-expressing type 2 cells are immunoreactive for GABA (arrowheads). E, F, GFP-positive type 2 cell somata are immunoreactive for calretinin (arrowheads). Type 2 cells stratify between sublaminae 2 and 3 of the IPL and contribute to the middle calretinin-positive band. Layers are numbered in $\boldsymbol{E}$. G, H, GFP-expressing type 2 cells stratify in an area (arrow) in which only few bipolar cell terminals, stained with an antibody against VGluT-1, are present. EGFP, Enhanced green fluorescent protein; IPL, inner plexiform layer; ONL, outer nuclear layer; OPL, outer plexiform layer. Scale bars, $20 \mu \mathrm{m}$.

ously for DA cells in the mouse (Ballesta et al., 1984; Gustincich et al., 1997; Contini et al., 2010).

A second population of GFP-positive neurons stratifying in the middle of the IPL had its somata in the INL and, occasionally, displaced in the GCL (Fig. $1 A$, arrowheads). Since these GFP- 


\section{Table 2. Properties of type 2 cells}

\begin{tabular}{lc}
\hline Dendritic field size small diameter $/ \mu \mathrm{m}$ & $695 \pm 148$ (7 cells) \\
Dendritic field size large diameter $/ \mu \mathrm{m}$ & $1048 \pm 199$ (7 cells) \\
Dendritic field area/mm ${ }^{2}$ & $0.57 \pm 0.17$ (7 cells) \\
Soma size diameter $/ \mu \mathrm{m}$ & $9.5 \pm 1.1$ (119 cells) \\
Cell density/cells $\times \mathrm{mm}^{-2}$ & $243 \pm 58$ (36 fields from 3 retinas), central to \\
& peripheral gradient \\
Neurotransmitter & GABA, catecholamine? \\
Marker & Calretinin, calbindin, PEP-19 \\
Resting membrane potential $/ \mathrm{mV}$ & $-50.7 \pm 3.8$ (38 cells) \\
Light response & ON-0FF response with an early transient \\
& component and late, more sustained components \\
Receptive field & Without functional subdivision \\
\hline
\end{tabular}

All values are given as mean \pm SD; numbers in parantheses give the $n$ value.

positive cells were considerably brighter than DA cells, GFP brightness served as a reliable criterion to target type 2 cells specifically. Type 2 cell somata had significantly smaller diameters than DA cells (diameter, $9.5 \pm 1.1 \mu \mathrm{m} ; n=119 ; p=0.0087, t$ test). Somata in both the INL and the GCL were negative for TH (Fig. $1 B$ ). This is in line with previous reports (Zhang et al., 2004; Contini et al., 2010), which also showed that this cell population is not immunoreactive to the TH antibody. Since these cells have been described morphologically in a transgenic mouse line that expressed a similar construct (TH::RFP, Zhang et al., 2004), we adopted the name and refer to these cells as type 2 cells.

\section{Type 2 cells in the INL and GCL are GABA-immunoreactive}

Since DA cells are not only dopaminergic but also use GABA as a neurotransmitter (Wässle and Chun, 1988), we tested for neurotransmitter expression in GFP-positive type 2 cells. Cryosections from a TH::GFP retina were labeled for GABA. Consistent with previous work (Haverkamp and Wässle, 2000), the antibody against GABA stained somata in the INL and GCL and several strata in the IPL (Fig. 1C). GFP-positive type 2 cells in both the INL and the GCL were always positive for GABA immunoreactivity (Fig. 1D). We also tested for the expression of glycine but did not find any colocalization with GFP-positive cells (data not shown).

In rat, type 2 cells have been shown to be positive for phenylethanolamine $N$-methyltransferase, the epinephrine biosynthetic enzyme (Park et al., 1986). Yet, antibodies against phenylethanolamine $N$-methyltransferase failed to stain type 2 cells in the mouse retina (data not shown), as reported previously (Zhang et al., 2004). Staining with antibodies against the vesicular monoamine transporter 2 did not show any colocalization with GFP-positive type 2 cell processes, whereas DA cells showed strong colocalization (data not shown). These data suggest that type 2 cells use GABA as a principal neurotransmitter. Whether they also use a catecholamine remains unclear (see Discussion, below).

\section{Cell morphology and stratification pattern}

To elucidate the cell morphology of type 2 cells, we injected Neurobiotin into GFP-positive type 2 cells in the INL and GCL. Both subpopulations of cells showed similar, slightly asymmetric, extensive dendritic arbors (Table 2), which stratified exclusively between sublaminae 2 and 3 of the IPL. Consistent with Zhang et al. (2004), we never observed dye coupling among type 2 cells, although dye coupling experiments were performed under light conditions that regularly showed dye coupling for other amacrine cells (G. Knop, unpublished observation). Staining with antibodies against calretinin (Fig. $1 E$ ) revealed that type 2 cell stratification between layers 2 and 3 coincided with the second calretinin band (Fig. $1 F$ ). Calretinin labels several amacrine cell and ganglion cell somata in the INL and GCL (Haverkamp and Wässle, 2000). One of the populations labeled by calretinin comprises type 2 cells, since type 2 cell bodies in the INL and GCL were positive for calretinin (Fig. $1 F$, arrowheads). To facilitate comparisons with other amacrine cell types, we stained retinas with other amacrine cells markers and found that type 2 cells were also positive for calbindin and Pep19 (data not shown).

\section{Immunohistochemical analysis of inputs to type 2 cells}

Mariani (1991) reported that type 2 cells receive inputs from bipolar cells and amacrine cells in the monkey retina. To test for bipolar cell inputs, we stained cryosections from TH::GFP retinas with antibodies against vesicular glutamate transporter (VGluT) 1. As described previously (Johnson et al., 2003), VGluT1 is strongly expressed in photoreceptor terminals in the outer plexiform layer and in bipolar cell terminals in the IPL (Fig. $1 G$ ). As visible in Figure $1 H$ (arrow), GFP-positive type 2 cells stratify in the IPL in an area where only a few bipolar cell processes terminate (the watershed between ON and OFF sublamina), suggesting that type 2 cells may receive predominantly amacrine cell input. This has already been suggested by Mariani (1991), who used electron microscopy to study type 2 cells in the primate retina. However, since the VGluT1 staining also revealed costratification of bipolar cell and GFP-filled type 2 terminals, we further analyzed putative bipolar cell inputs to type 2 cells. For this purpose, we used markers for bipolar cell types that stratify in sublaminae 2 and 3. These are types 3 and 4 OFF bipolar cells and type 5 ON bipolar cells (Ghosh et al., 2004; Wässle et al., 2009). Since calsenilin, the marker for type 4 OFF bipolar cells, stains not only bipolar cell terminals but also amacrine cell terminals (Haverkamp et al., 2008), we only tested for type 3 OFF and type 5 ON bipolar cells. We used CaB5 as a marker for these cells, which also stains rod bipolar cells (Haverkamp et al., 2003). To visualize glutamatergic ribbon synapses between bipolar cells and type 2 cells, we used an antibody against C-terminal binding protein 2 (Schmitz et al., 2000). Staining retinal cryosections from TH::GFP mice with these markers (Fig. 2) showed that the axon terminals of type 3 OFF (sublamina 2) and type 5 ON bipolar cells (sublaminae $3 / 4$ ) not only costratified with GFP-filled type 2 cell processes but also showed immunoreactive puncta positive for CtBP2 at contact sites. Figure 2, F-I, shows examples of ribbon synapses between type 2 cells and CaB5-immunoreactive terminals (arrows and arrowheads). These terminals most likely belong to type $3 \mathrm{OFF}$ and $5 \mathrm{ON}$ bipolar cells, since the CaB5-positive dendrites make contact either from more distal parts of the IPL (putative OFF bipolar cells) or from more proximal parts of the IPL (putative ON bipolar cells).

To control for true colocalization, we performed three analyses: 1$)$ we rotated the confocal stacks around the $x$-axis to find CtBP2-positive puncta adjacent to or colocalized with GFPpositive terminals, 2) we counted these puncta, and 3) we performed an object-based colocalization analysis. For this purpose, we calculated the pixel intensity along a straight line placed across the putative contact site (Fig. $2 I$, dashed lines). If the pixel intensity of the blue and red channel reached a defined threshold, we normalized pixel intensity and analyzed whether or not the CtBP2-positive punctum was associated with a CaB5-positive bipolar cell terminal (for details, see Materials and Methods, above). Of the 185 potential contact sites on four different cells that were analyzed in this way, $31 \pm 7 \%$ sites were associated with 

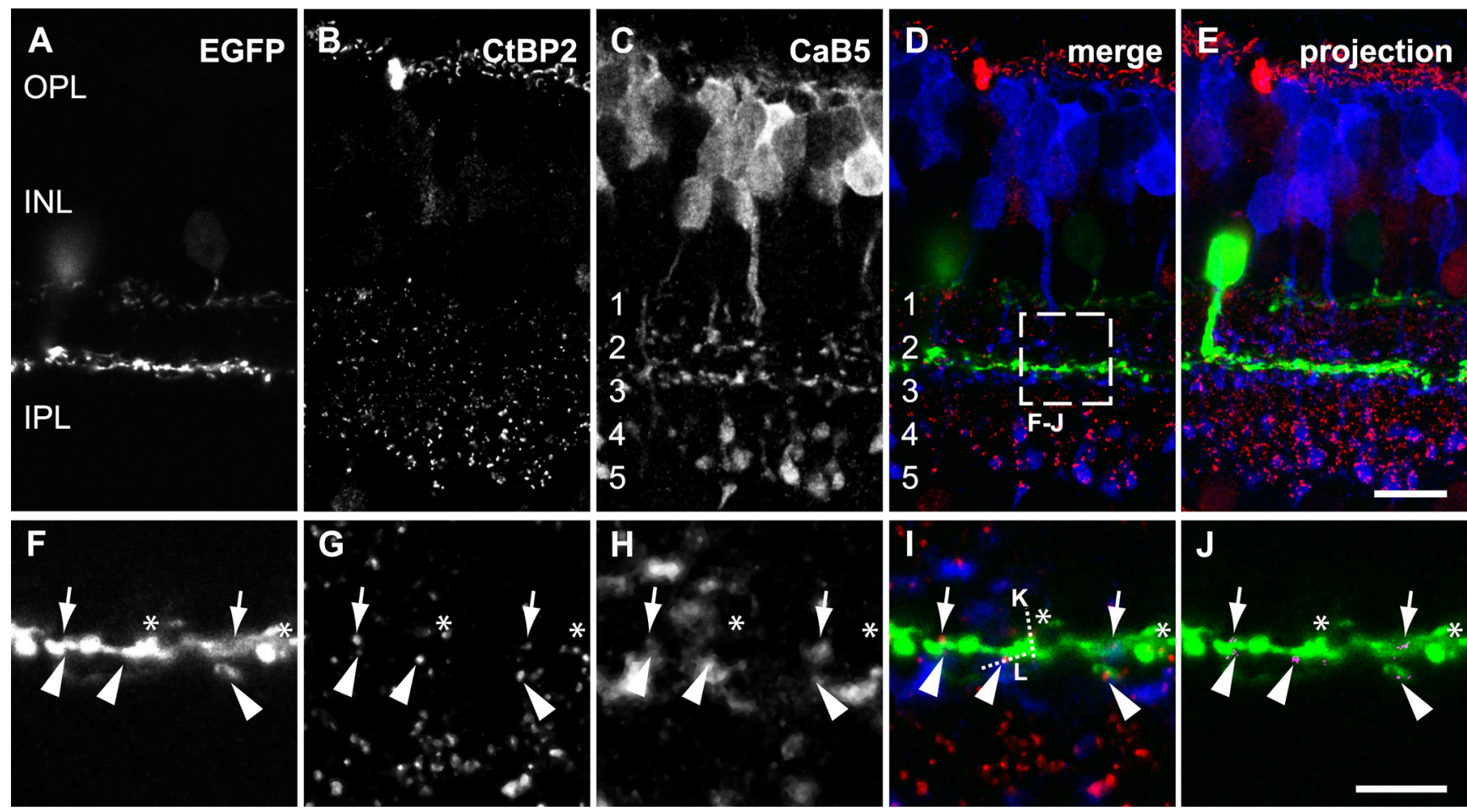

K

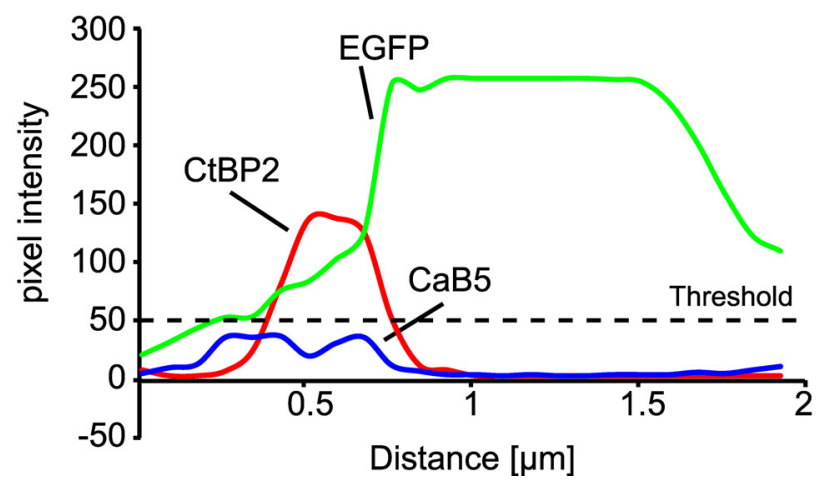

$\mathbf{L}$

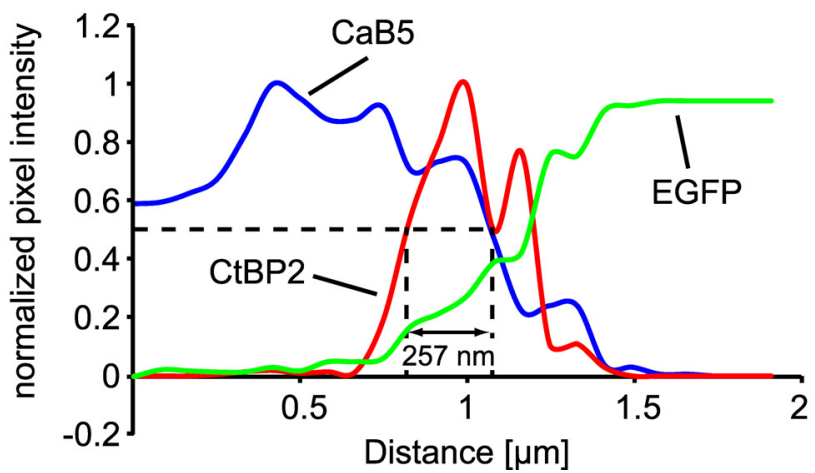

Figure 2. Type 2 cells receive inputs from CaB5-immunoreactive bipolar cells. $\boldsymbol{A}-\boldsymbol{D}$, Single confocal scans $(0.2 \mu \mathrm{m})$ of a retina section from a TH::GFP mouse $(\boldsymbol{A})$ labeled with antibodies against the synaptic ribbon marker $\mathrm{CABP} 2(\boldsymbol{B})$ and $\mathrm{CaB5}(\boldsymbol{C})$, a bipolar cell marker. Type 2 cells occasionally contact $\mathrm{CaB5}$-immunoreactive bipolar cell terminals. Individual ribbon synapses are visible at contact points. The superimposed square in $\boldsymbol{D}$ is shown under higher magnification in $\boldsymbol{F}-\boldsymbol{J}$. $\boldsymbol{E}$, Projection of 15 confocal scans (thickness, $3 \mu \mathrm{m}$ ). $\boldsymbol{F}$ - $\boldsymbol{I}$, The GFP-expressing type 2 dendrite contacts CaB5-positive bipolar cell terminals from both proximal (arrowheads) and distal (arrows) layers in the IPL. At contact points, CtBP2-positive glutamatergic ribbon synapses are present on the bipolar cell side (arrows and arrowheads). However, there are also CtBP2-positive puncta adjacent to the GFP-positive type 2 cell terminal that do not colocalize with CaB5. These structures are labeled with asterisks and presumably represent excitatory synapses between other bipolar cell types and type 2 cells. J, Colocalized points from all three channels are highlighted in magenta and projected onto the type 2 cell terminal. $\boldsymbol{K}$,, , Pixel intensity plots for the area marked by dashed lines in $\boldsymbol{I} \boldsymbol{K}$, Pixel intensity of the blue channel (CaB5) did not reach the predefined threshold (dashed line). Therefore, no colocalization was assumed. L, Pixel intensity of all channels was larger than threshold (data not shown) and was normalized and plotted against distance. Following Bolte and Cordelières (2006), we defined colocalization between the bipolar cell marker (blue) and the synaptic marker (red) as when the true overlap distance (arrow) of the normalized fluorescence intensity curves at mid-height (dashed line) was larger than $\sim 245 \mathrm{~nm}$ (lateral resolution of the $63 \times$ objective). In this example, overlap distance was $257 \mathrm{~nm}$, indicating the presence of an excitatory synapse at contact points between CaB5-positive and type 2 cell terminals. Note that intensity values for EGFP are only shown to illustrate the spatial relationship between all three stainings. For details, see Materials and Methods. OPL, Outer plexiform layer; EGFP, enhanced green fluorescent protein. Scale bars: $\boldsymbol{A}-\boldsymbol{E}, 10 \mu \mathrm{m} ; \boldsymbol{F}-\boldsymbol{J}, 5 \mu \mathrm{m}$.

CaB5-positive bipolar cell terminals. However, $69 \pm 7 \%$ potential contact sites were not associated with CaB5-positive structures, suggesting that type 2 cells also receive substantial excitatory input from other cells, most likely other bipolar cells. In Figure 2, F-J, these structures are marked with asterisks. In Figure 2, $K$ and $L$, two examples of pixel intensity plots are shown. In the first example (Fig. $2 \mathrm{~K}$ ), pixel intensity of the blue channel (CaB5 staining) did not reach threshold; therefore, it was concluded that the CtBP2-positive punctum and the CaB5-positive dendrite did not colocalize. In the second example (Fig. 2 L), pixel intensity values passed threshold, were normalized, and passed the criterion for true colocalization, indicating that the CtBP2positive punctum was indeed associated with a CaB5-positive bipolar cell terminal.

Both type $5 \mathrm{ON}$ and type 3 OFF bipolar cells fall into two subtypes whose axon terminals show a territorial behavior (Wässle et al., 2009). Though we used markers (HCN4, provided by Dr. Frank Müller, Jülich, Germany; and PKARII $\beta$, BD Transduction Laboratories) to separate type $3 \mathrm{a}$ and $3 \mathrm{~b}$ OFF bipolar cells, it was not possible to reliably determine the subtype since both markers failed to stain axon terminal tips. Together, these data suggest that type 2 cells receive glutama- 
A
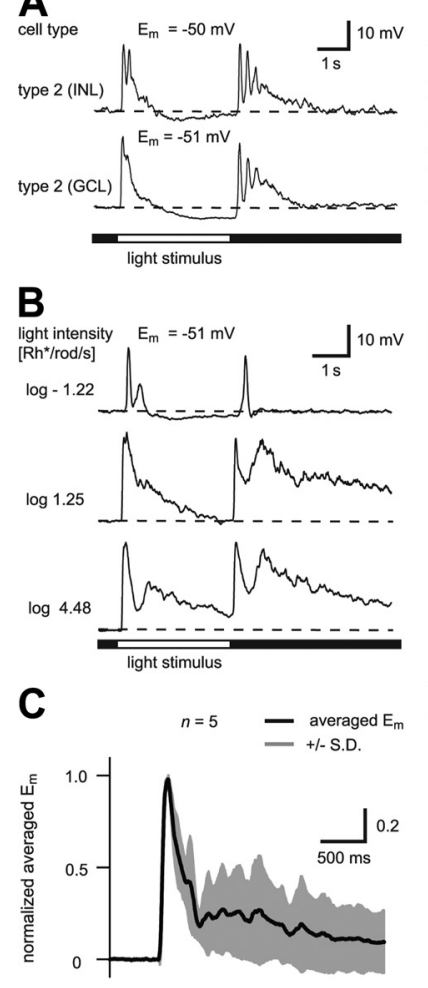

D

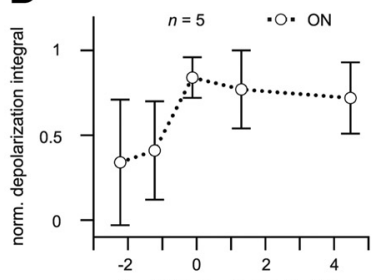

log light intensity $\left[R h^{*} / \mathrm{rod} / \mathrm{s}\right]$

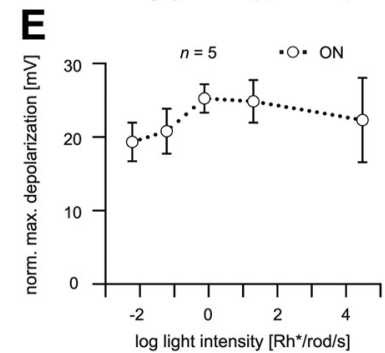

$\mathbf{F}_{30}$

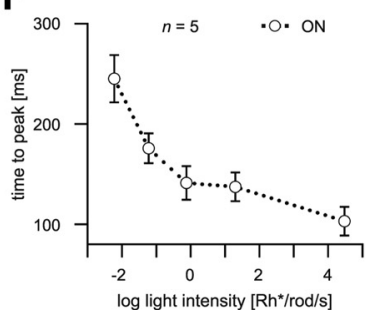

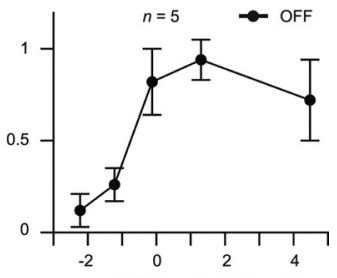

log light intensity $\left[\mathrm{Rh}^{*} / \mathrm{rod} / \mathrm{s}\right]$
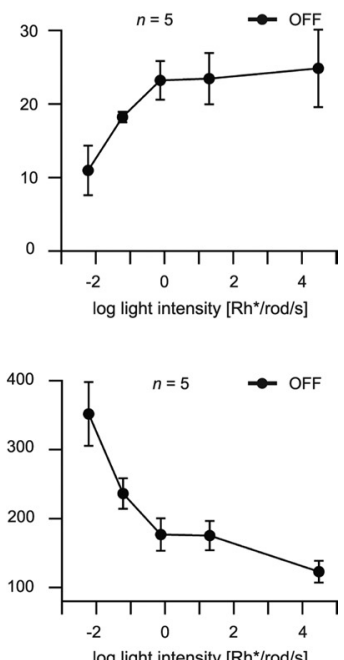

Figure 3. ON-OFF response characteristics and light sensitivity of type 2 cells. $A$, Representative light responses from a type 2 cell from the INL (top) and from the GCL (bottom). Cells were measured in the current-clamp mode and showed similar resting membrane potentials $\left(\mathrm{E}_{\mathrm{m}}\right)$. Both cells responded almost identically to a 3 s light stimulus $(0.8 \mathrm{Rh} / \mathrm{rod} / \mathrm{s})$, with strong depolarizations at the beginning and the end of the stimulus. $\boldsymbol{B}$, Representative light responses to three different light intensities (low scotopic, high scotopic, and mesopic) from a type 2 cell (GCL). Sustained response components increased with higher light intensities. C, Normalized ON responses to a full-field stimulus of $180 \mathrm{Rh} / \mathrm{rod} / \mathrm{s}$ of five cells. Average membrane potential waveform in black, SD in gray. Variability of light responses strongly increases after the first transient depolarization. All values are given as mean $\pm S D, n=5$. D. Intensity-response relationships measured as the normalized (norm.) depolarization integral for the $3 \mathrm{~s}$ after light $\mathrm{ON}$ (left) and $\mathrm{OFF}$ (right). ON depolarizations showed no significant change with stimulus intensity (ON: $p=0.02 ; 0 \mathrm{FF}$ : $p=5 \times 10^{-8} ; n=5$; one-way ANOVA). $\boldsymbol{E}$, Maximum (max.) depolarization of the transient component of ON (left) and OFF responses (right) as a function of stimulus intensity. $0 \mathrm{~N}$ depolarizations showed no significant change with stimulus intensity (ON: $p=0.06 ; 0 \mathrm{FF}: p=1 \times 10^{-5} ; n=5$; one-way ANOVA). $\boldsymbol{F}$, Time to peak for the transient component of ON (left) and OFF (right) responses as a function of stimulus intensity. Time to peak depolarization steadily decreased from low scotopic to mesopic intensities (ON: $p=4 \times 10^{-10} ;$ OFF: $p=4 \times 10^{-10} ; n=5$; one-way ANOVA). $\mathrm{E}_{\mathrm{m}}$ gives the resting membrane potential.

tergic inputs from both type $5 \mathrm{ON}$ and type 3 OFF bipolar cells and presumably from other bipolar cells.

\section{Light-evoked responses of type 2 cells}

To further analyze the inputs to type 2 cells, we used whole-cell patch-clamp recordings from the dark-adapted whole-mount retina. With the help of two-photon excitation, we were able to target individual GFP-expressing cells in both the INL and GCL and to record light responses (for details, see Materials and Methods, above). Cells were measured in the current-clamp mode and responded to a $3 \mathrm{~s}$ scotopic light stimulus with a strong depolarization at the beginning and the end of the light stimulus $(0.8$ $\mathrm{Rh}^{\star} / \mathrm{rod} / \mathrm{s}$ ) (Fig. 3A). Most ON-OFF amacrine cells show spikes in response to light stimuli (Freed et al., 1996; Stafford and Dacey, 1997; Bloomfield and Völgyi, 2007). However, for type 2 cells, we never observed spikes riding on top of the depolarization. Both ON and OFF responses started with a prominent transient potential, which lasted $\sim 300 \mathrm{~ms}$ and was $15-25 \mathrm{mV}$ in amplitude. This was followed by secondary, more sustained response components, which showed considerable variation between individual cells (Fig. 3). During the ON response, the membrane potential returned to baseline or even lower well before stimulus end. Patch-clamp recordings from type 2 cells in the INL and GCL showed similar light responses, with a transient peak followed by a more sustained response (Fig. 3A). We only recorded from type 2 cells in the GCL in subsequent experiments since these cells were easier to access.

To analyze the range of light intensities in which type 2 cells can operate, we measured light responses to full-field stimuli of varying intensity. Figure $3 B$ shows representative responses to three different light intensities (low scotopic, $0.06 \mathrm{Rh}^{\star}$ / $\mathrm{rod} / \mathrm{s}$; high scotopic, $17.8 \mathrm{Rh}^{\star} / \mathrm{rod} / \mathrm{s}$; mesopic, $\left.3 \times 10^{4} \mathrm{Rh}^{\star} / \mathrm{rod} / \mathrm{s}\right)$. Note that even at very low light intensities, the light response consisted of an early transient component. When light intensity increased, more complex response components occurred. To account for all response components, we first analyzed the total depolarization integral during light stimulus presentation (ON) (Fig. $3 D$, left) and after light stimulation (OFF) (Fig. 3D, right). However, late response components showed so much variability between individual cells (Fig. $3 C$ ) that this parameter did not represent stimulus characteristics reliably. We therefore concentrated our quantitative analysis on amplitude and timing of the early transient potentials. Maximum depolarization (Fig. 3E) and time to peak depolarization (Fig. $3 F$ ) of the early transient response showed much less variability. However, maximum depolarization for $\mathrm{ON}$ and OFF responses only slightly increased upon increasing light intensity (Fig. 3E); ON and OFF responses reached saturation well within the high scotopic range, indicating that maximum depolarization has a rather narrow dynamic range under full-field stimulation. In contrast, time to peak depolarization consistently decreased over the entire range of increasing light intensities (Fig. $3 F$ ). These data suggest that time to peak, rather than maximum depolarization, is the relevant parameter for encoding light intensities up to the mesopic range. Interestingly, OFF responses were slower than $\mathrm{ON}$ responses in all light conditions, potentially reflecting temporal differences in the underlying inputs. However, temporal differences between $\mathrm{ON}$ and OFF responses most likely arise from a technical limitation in our light stimulation, since stimuli were delivered by a CRT monitor. Due to the afterglow of the CRT monitor's aperture mask, the presentation of negative contrast (i.e., the OFF stimulus) most likely had a shallower time course than the ON stimulus. Also, the OFF response was often preceded by a long-standing hyperpolarization. Thus, it is possible that this could delay the time it takes the cell to reach its peak depolarization compared with the response at light onset, which arises from the resting membrane potential. Therefore, we restricted the investigation of $\mathrm{ON}$ and $\mathrm{OFF}$ differences to our pharmacological experiments (see Glutamate- dependent inputs to type 2 cells, below). 
Receptive field properties of type 2 cells To analyze the receptive field properties of type 2 cells, we first used concentric spots of increasing size at a light intensity of 17.8 $\mathrm{Rh}^{*} / \mathrm{rod} / \mathrm{s}$ (high scotopic). Figure $4 A$ shows representative responses of a type 2 cell to three different spot sizes. With an increase in stimulation area, response components became more complex. Again, depolarization integral and maximum depolarization poorly reflected stimulus variation (data not shown). In contrast, time to peak depolarization consistently decreased with increasing stimulus area (Fig. 4B). ON and OFF responses were neither attenuated (data not shown) nor delayed during large spots $(>0.2$ $\mathrm{mm}^{2}$ ). This suggests that surroundmediated inhibition does not contribute substantially to type 2 cells' receptive fields. However, the area-integration paradigm uses the central part of the dendritic field for every stimulus. This could potentially mask a nonuniform distribution of ON and OFF inputs along type 2 cell dendrites, especially if inputs near the recording pipette dominated the light response. To account for this, we used the same light intensity as before but stimulated type 2 cells with three different stimuli, which had the same total area $(0.2$ $\mathrm{mm}^{2}$ ) but covered non-overlapping areas of the cell's dendritic field (Fig. 4C,D). If, for example, ON inputs were restricted to proximal regions, then a spot centered on the soma should elicit a larger ON response than two annuli covering areas in the distal dendritic field of the type 2 cell. Figure $4 C$ shows representative responses to the three different stimuli. Both $\mathrm{ON}$ and OFF responses looked very similar for all stimulus conditions, and indeed, none of the evaluated response parameters showed significant differences. In particular, time-to-peak depolarization, which varied consistently with light intensity and stimulation area, was the same for all stimulus positions $(p=0.1 \mathrm{ON}$ responses, $p=0.44$ OFF responses, one-way ANOVA; $n=8$ ). Together, these results suggest that $\mathrm{ON}$ and OFF inputs are distributed homogeneously along type 2 cell dendrites.

\section{Glutamate-dependent inputs to type 2 cells}

To further analyze excitatory inputs to type 2 cells, we combined light response recordings with pharmacology (Fig. 5). Since type 2 cells showed a high light sensitivity (Fig. 3), we presumed that rod pathways may provide input to type 2 cells (Völgyi et al., 2004). In the primary rod pathway, the rod signal is transmitted to rod bipolar cells, which synapse with AII amacrine cells. These small-field amacrine cells relay $\mathrm{ON}$ responses via electrical synapses with ON cone bipolar cells and OFF responses via glycinergic synapses with OFF cone bipolar cells or by direct glycinergic input to OFF ganglion cells. In the secondary rod pathway, the rod signal is transmitted via gap junctions to cones and is shunted from there into ON and OFF cone pathways (Völgyi et al., 2004). Thus, if the primary rod pathway indeed provides input to type 2 cells under low scotopic conditions (full-field stimulus, $0.8 \mathrm{Rh}^{\star} /$ $\mathrm{rod} / \mathrm{s}$ on top of a constant background of $0.6 \mathrm{Rh}^{\star} / \mathrm{rod} / \mathrm{s}$ ), blockade of glutamatergic signal transmission between rods and rod
B
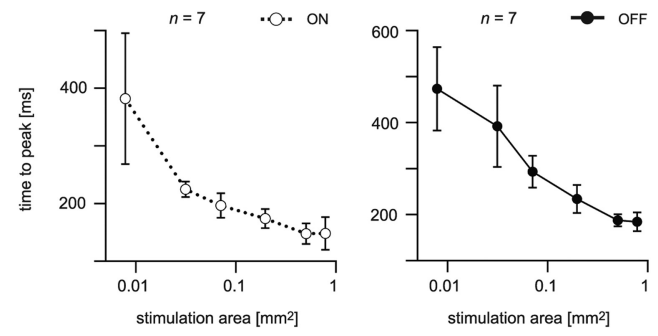

D
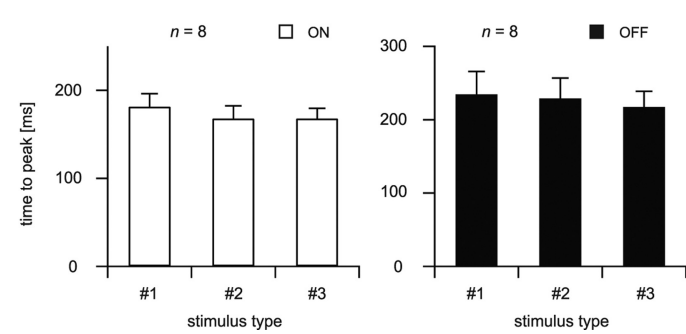

bipolar cells should eliminate both ON and OFF responses. We tested this hypothesis by measuring light responses of type 2 cells under control conditions and in the presence of L-AP4 $(100 \mu \mathrm{M})$, an mGluR6 agonist which blocks metabotropic glutamate receptors on ON bipolar cells. Application of L-AP4 completely abolished the ON response and strongly impaired the OFF response in type 2 cells, represented by the maximum depolarization amplitude (ON, $p=0.0001$; OFF, $p=0.001 ; n=6$; paired $t$ test) (Fig. $5 A, B$ ). Wash-out restored both light response components (Fig. $5 A, B$ ). These data show that under low scotopic conditions, a large portion of the light responses of type 2 cells is dependent on mGluR6 and thus is presumably mediated by the primary rod pathway. However, the less sensitive secondary rod pathway may also be active and contribute to ON and OFF light responses. Signals traveling from rods to cones and from there to OFF bipolar cells may account for the small L-AP4-resistant OFF response under low scotopic conditions (Fig. 5A,B).

To test which pathways provide input to type 2 cells under high scotopic conditions, we repeated the experiment with slightly increased stimulus intensity (full-field stimulus, $6 \mathrm{Rh}^{*}$ / $\mathrm{rod} / \mathrm{s}$ on top of a constant background of $\left.0.6 \mathrm{Rh}^{\star} / \mathrm{rod} / \mathrm{s}\right)$. Under these conditions, L-AP4 showed a differential effect on type 2 cells' light responses (Fig. 5C). First, L-AP4 completely blocked the early transient component of the $\mathrm{ON}$ response. This was again analyzed by evaluating the maximum depolarization of the first $300 \mathrm{~ms}$ of the ON response, which contain this first transient component ( $p=0.0001 ; n=7$; paired $t$ test) (Fig. $5 D$ ). Also, blockade with L-AP4 revealed a small transient hyperpolarization, possibly reflecting inputs from OFF bipolar cells. Second, a considerable fraction of the late $\mathrm{ON}$ response components was resistant to L-AP4 application (Fig. 5C). Third, L-AP4 did not significantly alter the OFF response $(p=0.15 ; n=7$; paired $t$ test $)$ 

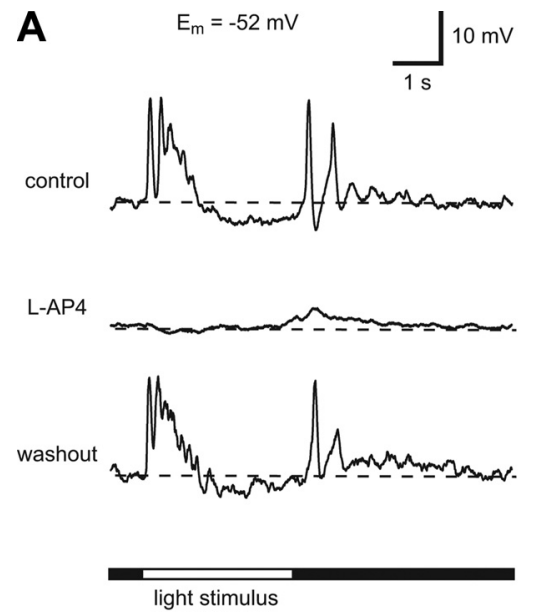

B

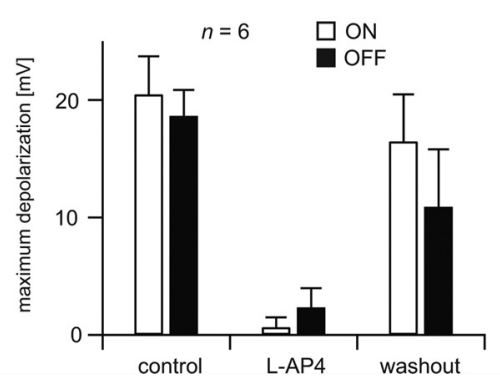

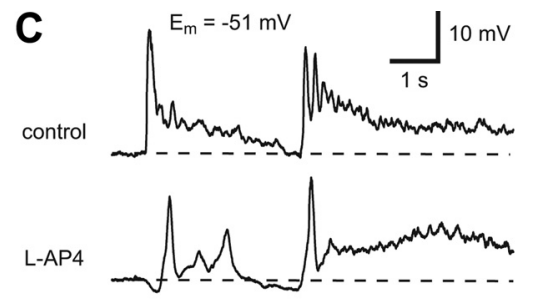

+ CNQX

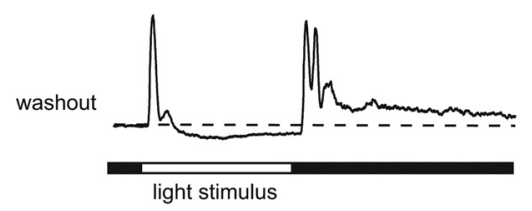

D

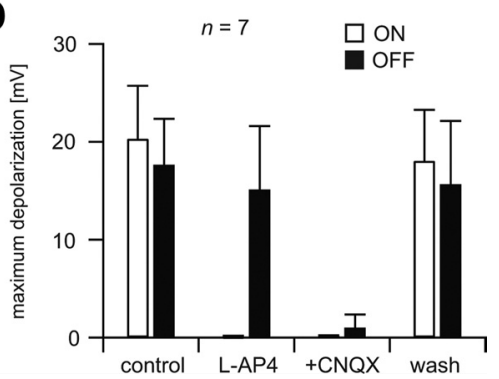

Figure 5. Blocking glutamatergic inputs to type 2 cells. $\boldsymbol{A}, \boldsymbol{B}$, Light responses from type 2 cells $(\mathrm{GCL})$ under low scotopic conditions ( $0.8 \mathrm{Rh}$ / $/ \mathrm{rod} / \mathrm{s}$; adapting background, $\left.0.6 \mathrm{Rh}^{*} / \mathrm{rod} / \mathrm{s}\right)$. L-AP4 (100 $\left.\mu \mathrm{m}\right)$ completely blocked the 0N component ( $p=$ $5 \times 10^{-5} ;$ paired $t$ test) and strongly impaired the OFF component ( $p=1 \times 10^{-4}$; paired $t$ test) of the response. Values in $\boldsymbol{B}$ are given as mean $\pm \mathrm{SD}, n=6$. C, Light responses from type 2 cells (GCL) under high scotopic conditions (6 Rh*/rod/s, adapting background $0.6 \mathrm{Rh}$ */rod/s). To block all excitatory inputs, first L-AP4 (100 $\mu \mathrm{m})$ and subsequently CNQX (100 $\mu \mathrm{m})$ were applied. D, Evaluation of the blocker effects on $\mathrm{ON}$ and $\mathrm{OFF}$ responses. Whereas the early transient $\mathrm{ON}$ component is completely blocked by L-AP4 ( $p=7 \times 10^{-7} ; n=7$; paired $t$ test), the early transient OFF component is unimpaired ( $p=0.15 ; n=7$; paired $t$ test). However, after additional CNQX application, all ON and OFF components are blocked. Values in $D$ are given as mean \pm SD, $n=7$. $\mathrm{E}_{\mathrm{m}}$, Resting membrane potential.

(Fig. 5D). These data show that under high scotopic conditions, type 2 cells receive inputs independent of the primary rod pathway. Other rod pathways or even cone pathways must come into play.

To test this, we repeated the experiment with the same light conditions but applied L-AP4 to block mGluR6-dependent response components and then applied the AMPA/kainate glutamate receptor antagonist CNQX $(100 \mu \mathrm{M})$ to block response components that are mediated by ionotropic glutamate receptors (Fig. $5 C, D)$. As expected, subsequent application of glutamate receptor blockers completely abolished light responses of type 2 cells, indicating that under high scotopic conditions, OFF bipolar cells receive direct input from photoreceptors and in turn provide input to type 2 cells. Interestingly, CNQX blocked the L-AP4resistant secondary ON component (Fig. 5D). Since the only remaining pathway that is known to be CNQX-sensitive is the OFF pathway, inhibition of OFF bipolar cells at light onset creates a crossover excitation which is presumably mediated by some amacrine cell circuit. Similar effects of L-AP4 and CNQX have been reported for ON-sustained DA cells (Zhang et al., 2007). Effects of both blockers were in part reversible. Very similar results were obtained when stimulus intensity was increased further (full-field stimulus, $3 \times 10^{4} \mathrm{Rh}^{\star} / \mathrm{rod} / \mathrm{s}$ on top of a constant background of $600 \mathrm{Rh}^{\star} / \mathrm{rod} / \mathrm{s}$, mesopic) (data not shown).

We conclude that type 2 cells receive excitatory inputs from $\mathrm{ON}$ and OFF cone bipolar cells, which in turn obtain their signals either via the primary rod pathway (low scotopic), the secondary rod pathway (low/high scotopic), or directly from photoreceptors (high scotopic/mesopic). During the early ON response, type 2 cells most likely also receive inhibitory inputs from amacrine cells.

\section{Glycine- and GABA-dependent inputs to type 2 cells}

To further analyze putative inputs from amacrine cells, we measured light responses of type 2 cells under control conditions and in the presence of the glycine receptor blocker strychnine (1-2 $\mu \mathrm{M}$; fullfield stimulus, $6 \mathrm{Rh}^{\star} / \mathrm{rod} / \mathrm{s}$ ). Figure $6 \mathrm{~A}$ shows a representative example. Similar results were obtained for three cells; after 3 min of strychnine wash-in, type 2 cells were depolarized by 3-5 $\mathrm{mV}$ and showed membrane potential oscillations with an amplitude of $>15 \mathrm{mV}$ and a frequency of $3 \mathrm{~Hz}$ (Fig. 6A). Oscillations were almost independent of the light stimulus, which only evoked slight changes in oscillation frequency during the light stimulus and a reduction of oscillations immediately after stimulus end. These results suggest that type 2 cells are influenced by a glycinergic circuitry.

To test whether type 2 cells also receive inhibition from GABAergic amacrine cells, we applied bicuculline $(100 \mu \mathrm{M})$ (Fig. $6 \mathrm{~B}$ ), a blocker of $\mathrm{GABA}_{\mathrm{A}}$ receptors (Ueno et al., 1997; Völgyi et al., 2004). Similar to strychnine, bicuculline led to membrane potential oscillations in six of six cells. However, oscillations only occurred during light stimulation. During the ON response, fast oscillations rode on top of the underlying membrane depolarization $(7-11 \mathrm{~Hz})$ (Fig. 6 B). At the end of the light stimulus (OFF response), oscillations were slower and ceased after a few periods. Together, type 2 cells are strongly influenced by glycinergic and GABAergic amacrine cells, which may provide direct or indirect input to type 2 cells.

\section{Costratification with VGluT3-positive amacrine cells}

Application of strychnine showed that type 2 cells are influenced by glycinergic amacrine cells. Therefore, we tested for direct glycinergic inputs to type 2 cells using immunohistochemistry. As VGluT3-positive amacrine cells are glycinergic and stratify in the same layer as type 2 cells (Haverkamp and Wässle, 2004), we stained TH::GFP retinas for VGluT3 and the glycine receptor subunit $\alpha 2$ (GlyR $\alpha 2)$, which was shown to be postsynaptic to VGluT3-positive amacrine cell terminals (Haverkamp et al., 2004). Figure 7 shows that type 2 cell processes (Fig. $7 A, F$ ) are in close vicinity to VGluT3-positive amacrine cell processes (Fig. $7 B, G)$. Moreover, at contact sites, we found immunoreactive puncta for GlyR $\alpha 2$ (Fig. 7C,D, $H-I$, arrowheads), indicating that type 2 cells receive glycinergic input from VGluT3-positive amacrine cells, which are also most likely ON-OFF amacrine cells (Haverkamp et al., 2004). We controlled for colocalization using the same methods as stated above. First, we identified regions in which GlyR $\alpha 2$ colocalized with GFP-positive type 2 cell dendrites 
A

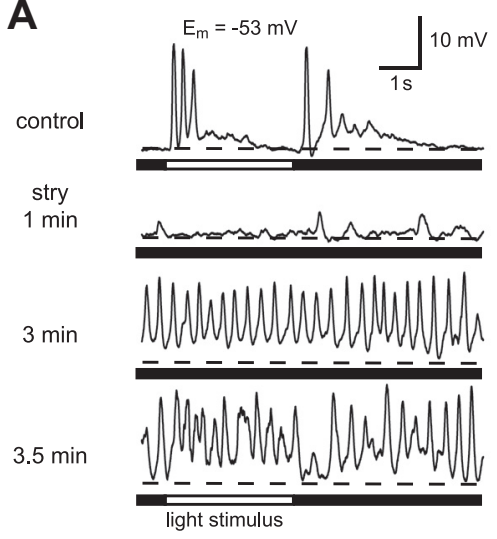

B

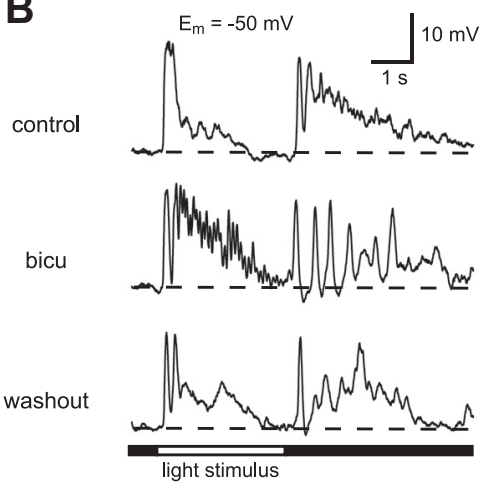

Figure 6. Blocking glycinergic or GABAergic inputs to type 2 cells. A, Light responses from type 2 cells $(\mathrm{GCL})$ under control conditions and after blocking glycine receptors with $1 \mu \mathrm{m}$ strychnine (stry). After $3 \mathrm{~min}$, the type 2 cell resonated in the presence of strychnine $(\sim 3 \mathrm{~Hz})$. Similar oscillations occurred in all cells tested $(n=3)$. The light stimulus ( $6 \mathrm{Rh} / \mathrm{rod} / \mathrm{s})$ led to only slight changes in oscillation frequency during the light stimulus and a reduction of oscillations immediately after stimulus end. $\boldsymbol{B}$, Light responses from type 2 cells $(\mathrm{GCL})$ under control conditions and after blocking $\mathrm{GABA}_{A}$ receptors with $100 \mu \mathrm{m}$ bicuculline (bicu). Bicuculline led to membrane potential oscillations during and after the light stimulus. During light stimulus presentation, the early transient depolarization was followed by a series of high-frequency oscillations (7-11 Hz). After stimulus offset, oscillation frequency was lower and oscillations ceased after a few periods. Similar effects were observed in all measured cells $(n=6)$. $E_{m^{\prime}}$ Resting membrane potential.

(Fig. 7J). Second, rotation of confocal stacks around the $x$-axis served to control for colocalization (data not shown). Third, putative contact sites were analyzed for true colocalization and contact to VGluT3-positive amacrine cell terminals using line scans (Fig. $7 K, L$ ). Of the 123 putative contact sites on three different type 2 cells that were analyzed in this way, $52 \pm 12 \%$ were associated with VGluT3-positive amacrine cell terminals. However, $48 \pm 12 \%$ of the GlyR $\alpha 2$-positive puncta were not associated with VGluT3-positive structures, suggesting that type 2 amacrine cells also receive glycinergic inputs via GlyR $\alpha 2$ from other glycinergic amacrine cells. In Figure 7, $K$ and $L$, two examples of pixel intensity plots are shown; in both cases, the GlyR $\alpha 2$-positive punctum was indeed associated with a VGluT3-positive amacrine cell terminal.

\section{Discussion}

Here we provide the first characterization of type 2 cells' light responses and receptive field properties. We have also analyzed their underlying inputs under different light conditions. Type 2 cells receive excitatory inputs from type 3 OFF and type 5 ON bipolar cells and presumably receive inhibitory inputs from both GABAergic and glycinergic amacrine cells.

\section{Comparison with other species}

Using a TH::GFP mouse line, we found two different populations of amacrine cells that expressed the GFP reporter under the TH promoter. One population comprised DA cells, which showed all characteristics (TH-immunoreactivity, stratification in sublamina 1, large somata, interplexiform dendrites, sparse distribution) that have been described before (Versaux-Botteri et al., 1986; Gustincich et al., 1997; Zhang et al., 2008). The second population of GFP-expressing cells comprised WFA cells, whose properties are summarized in Table 2. These cells were immunonegative for $\mathrm{TH}$ but had similar properties (stratification depth, soma, and dendritic tree size) as type 2 cells, which have been described in several species (Park et al., 1986; Mariani, 1991; Oh et al., 1999; Zhang et al., 2004, Contini et al., 2010). In the mouse, however, type 2 cells have never been found to be catecholaminergic (Zhang et al., 2004; Contini et al., 2010; present study), though the analysis may suffer from low catecholamine levels or type 2 cell-specific enzyme isoforms that may not be detected with the antibodies available (Versaux-Botteri et al., 1986).

\section{Subpopulations in INL and GCL have the same properties}

In the murine retina, several types of amacrine cells have most of their somata located in the INL but displace a small fraction of all somata into the GCL (Lin and Masland, 2006; Majumdar et al., 2008), e.g., A17 cells (Pérez De Sevilla Müller et al., 2007). This is also true for type 2 cells. Several independent lines of evidence suggest that type 2 cells in the INL and those in the GCL belong to the same population of amacrine cells. Both subpopulations stratify in the same layer of the IPL; have the same dendritic field size; contribute to the second calretinin band and are immunopositive for calretinin, Pep19, and calbindin; use GABA as a neurotransmitter; and show similar ON and OFF light responses, which most likely result from the same inputs. Thus, it seems reasonable to assume that the physiological characteristics of the type 2 cells from the GCL also apply to the type 2 cells in the INL.

\section{Receptive field properties of type 2 cells}

Consistent with their stratification in sublaminae 2 and 3 of the IPL, type 2 cells showed ON-OFF light responses. Using concentric spots of light, we first measured the area summation of type 2 cells and evaluated the depolarization maximum and time to peak as response parameters. We found no indication for an unequal distribution of excitatory or inhibitory inputs in this stimulus paradigm. For a more detailed analysis, we used a spot and two annuli that had the same area but covered nonoverlapping regions within the receptive field. Stimulus position did not alter depolarization maximum (data not shown) or time to peak depolarization (Fig. $4 D$ ). These data suggest that type 2 cells possess receptive fields without surround antagonism and that excitatory inputs are distributed homogeneously along type 2 cell dendrites, as was shown for other ON-OFF WFA cells before (Freed et al., 1996; Bloomfield and Völgyi, 2007). Moreover, these results indicate that type 2 cells, even though their dendrites are large, must be electronically compact if an annulus located on their more peripheral dendritic field can produce a response that is almost identical to a spot that covers the central part of the dendritic field.

\section{Type 2 cells receive glutamatergic inputs from $\mathrm{ON}$ and $\mathrm{OFF}$ cone bipolar cells}

We analyzed the excitatory inputs to type 2 cells using physiology and anatomy. At low light levels, type 2 cells most likely receive 


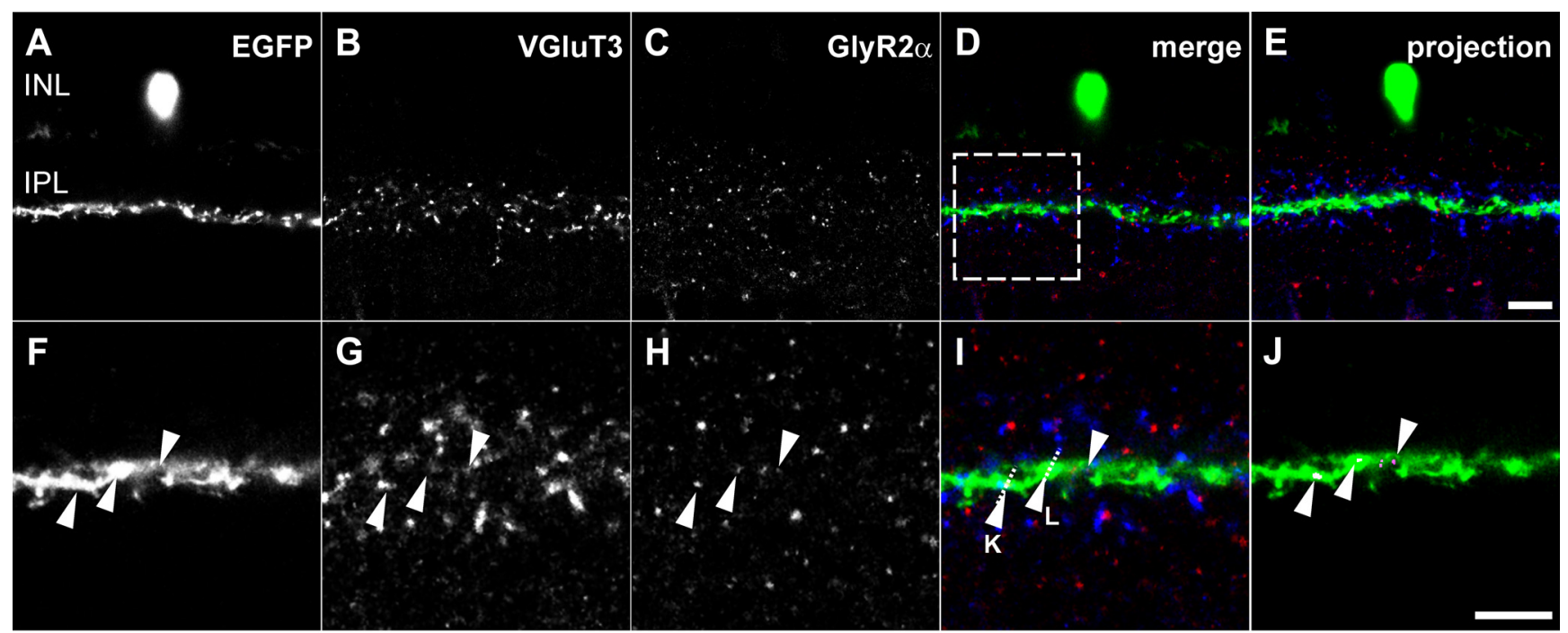

$\mathbf{K}$

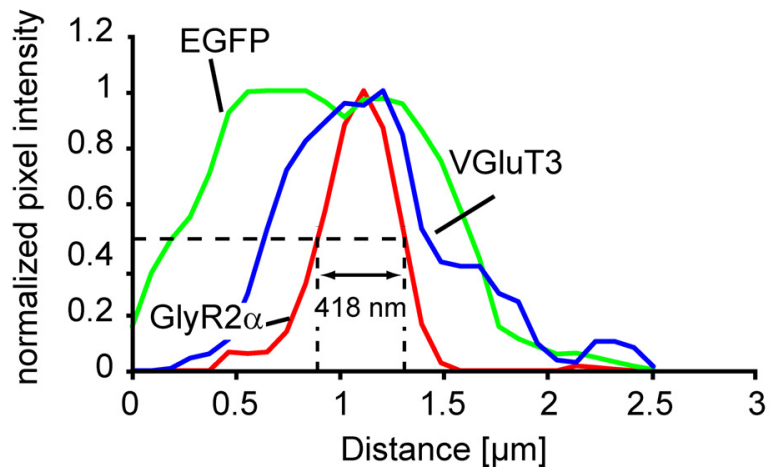

$\mathbf{L}$

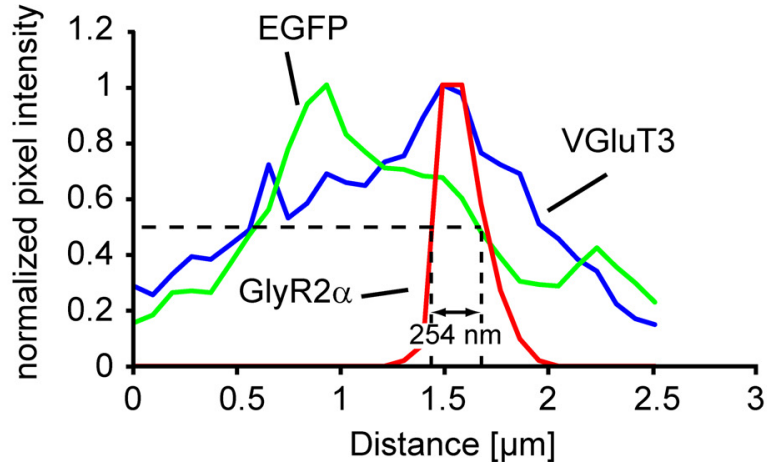

Figure 7. Type 2 cells receive inputs from VGluT3-immunoreactive amacrine cells and express glycine receptors. $A-D$, Single scans $(0.2 \mu \mathrm{m})$ of a retina section from a TH::GFP mouse labeled with antibodies against VGluT3, a marker for a certain type of glycinergic amacrine cell (B), and the glycine receptor $2 \alpha$ subunit (C). D, Merged image. $\boldsymbol{E}$, Projection of $15 \mathrm{scans}(3 \mu \mathrm{m})$. $\boldsymbol{F}$-J, Single confocal scans show the area marked in $\boldsymbol{D}$ under higher magnification. GFP-positive dendrites from type 2 cells $(\boldsymbol{E})$ are contacted by VGluT3-positive dendrites $(\boldsymbol{G})$. GlyR2 $\alpha$-positive puncta $(\boldsymbol{H})$ are visible at contact points between type 2 and VGluT3-positive amacrine cells $(\boldsymbol{I})$. $\boldsymbol{J}$, Colocalized points from all three channels are highlighted in magenta and projected onto the type 2 cell terminal (arrowheads). $\boldsymbol{K}, \mathbf{L}$, Pixel intensity plot for the area marked by dashed lines in $\mathbf{I}$. Pixel intensity was larger than threshold (for details, see Materials and Methods) and was normalized and plotted against distance. Following Bolte and Cordelières (2006), we defined colocalization between the type 2 cell dendrite (green) and the glycine receptor (red) as when the true overlap distance (arrow) of the normalized fluorescence intensity curves at mid-height (dashed line) was larger than $\sim 245 \mathrm{~nm}$ (lateral resolution of the $63 \times$ objective). For details, see Materials and Methods. Overlap distances of 418 and $254 \mathrm{~nm}$, respectively, confirmed the presence of glycine receptors at contact points between a glycinergic amacrine cell and GFP-positive type 2 cell terminals. Please note that intensity values for VGluT3 are only shown to illustrate the spatial relationship between all three stainings. Scale bars: $A-J, 10 \mu \mathrm{m}$.

inputs from the primary and secondary rod pathways. Because both ON pathways completely depend on mGluR6 signaling, L-AP4 completely abolished the ON response under low scotopic conditions (Fig. $5 A$ ). ON responses are presumably mediated by type 5 ON bipolar cells (Ghosh et al., 2004) since these cells contact type 2 cells in layer S3 of the IPL (Fig. 2 I). Moreover, we found synaptic ribbons at contact sites, indicating that type $5 \mathrm{ON}$ cells provide excitatory input to type 2 cells. L-AP4 also strongly impaired the OFF response of type 2 cells, indicating that part of the OFF response is mediated by the primary rod pathway. However, a small part of the OFF response was L-AP4-resistant, suggesting that OFF signals also reached type 2 cells via rod-cone coupling and OFF cone bipolar cells (secondary rod pathway). OFF responses could arise from type 3 OFF bipolar cells, which make synaptic contacts with type 2 cells in layer S2 of the IPL (Fig. $2 I$ ). However, only one-third of all CtBP2-positive puncta associated with type 2 dendrites belong to CaB5-positive bipolar cells; it is likely that other bipolar cell types, e.g., type 4 OFF bipolar cells, provide inputs as well. Both type 3 OFF cell subtypes and type 4 OFF bipolar cells have been shown to contact rods (Ghosh et al., 2004; Mataruga et al., 2007; Haverkamp et al., 2008), thereby providing an alternative rod pathway which may account for the small L-AP4-resistant OFF response of type 2 cells under low scotopic conditions (Fig. 5A,B).

This pathway may also be involved at slightly elevated light conditions (high scotopic), since L-AP4 application did not significantly impair the OFF response. However, under high scotopic conditions, the secondary rod pathway may also contribute to both ON and OFF responses since it has a low sensitivity. Direct cone pathways may also come into play.

\section{Type 2 cells are influenced by glycinergic and GABAergic} amacrine cells

Application of L-AP4 under high scotopic conditions did not completely abolish the $\mathrm{ON}$ response of type 2 cells (Fig. $5 C$ ). It showed a differential effect: the first transient component was completely abolished and a small hyperpolarization became visible, which may reflect direct input from OFF bipolar cells. The secondary ON response component, however, was at least in part L-AP4-resistant and most likely reflects an input from OFF bipolar cells through inhibitory amacrine cells, i.e., crossover inhibition (Hsueh et al., 2008; Molnar et al., 2009). Consistently, 
subsequent CNQX application completely blocked this component. Hsueh et al. (2008) recently reported that some ON-OFF amacrine cells receive OFF inhibition from other amacrine cells in the rabbit retina.

Since crossover inhibition is often mediated by glycinergic amacrine cells (Hsueh et al., 2008), we applied strychnine to block glycinergic transmission. Interestingly, type 2 cells began to resonate, a behavior that can be explained in several ways. Strychnine may act on glycinergic amacrine cells that provide input to presynaptic partners of type 2 amacrine cells, for example, bipolar cells. In this case, strychnine effects would be entirely presynaptic; membrane potential oscillations of type 2 cells may originate from resonating bipolar cell inputs (Schwartz and Berry, 2008). However, strychnine will primarily affect OFF bipolar cells since, in the mouse retina, ON cone bipolar cells do not appear to receive substantial glycinergic inputs (Ivanova et al., 2006). Since the ON and OFF responses of type 2 cells are similarly affected by strychnine application, another explanation seems more likely. Type 2 cells may receive glycinergic inputs that prevent membrane potential oscillations under normal conditions. Glycine has been shown to attenuate oscillatory potentials in bass WFA cells, which show fast $(70-140 \mathrm{~Hz})$ oscillatory potentials due to intrinsic membrane properties (Solessio et al., 2002). Glycinergic input to type 2 cells may be provided by VGluT3-positive amacrine cells, since these ONOFF amacrine cells cofasciculate with type 2 cells and type 2 cells show GlyR $\alpha 2$ subunits at contact sites. However, other glycinergic amacrine cells may contribute as well, since not all GlyR $\alpha 2$-positive structures were associated with VGluT3positive amacrine cell terminals.

As amacrine-to-amacrine cell inhibition can also be mediated by $\mathrm{GABA}_{\mathrm{A}}$ receptors, we applied the $\mathrm{GABA}_{\mathrm{A}}$ receptor blocker bicuculline to block GABAergic inhibition to type 2 cells. Bicuculline led to fast membrane potential oscillations during the $\mathrm{ON}$ response and slower but stronger oscillations during the OFF response, suggesting that type 2 cells are also influenced by GABAergic amacrine cells. Consistent with this, GABA has been shown to inhibit oscillatory potentials in WFA cells (Solessio et al., 2002). However, the effects of bicuculline on type 2 cells are difficult to interpret since they may be indirect. Bicuculline may act on a GABAergic amacrine cell that provides input to bipolar cells or it may inhibit a glycinergic amacrine cell providing input to type 2 cells. The decrease in the early ON response upon bicuculline application hints at this kind of disinhibition under control conditions. Hsueh et al. (2008) showed that one class of $\mathrm{ON}-\mathrm{OFF}$ amacrine cells receives a mixture of glycine and $\mathrm{GABA}_{A}$ receptor-mediated inputs. Type 2 cells most likely belong to this class of amacrine cells, in which both glycine receptors and $\mathrm{GABA}_{\mathrm{A}}$ receptors mediate serial connections and receive input from other amacrine cells.

In summary, we present here the first physiological characterization of type 2 cells. These GABAergic ON-OFF amacrine cells exhibit light responses that are remarkably uniform from scotopic to mesopic light conditions, suggesting that type 2 cell function is preserved under different adaptational states of the retina. Further analyses will have to elucidate the targets of type 2 cells' GABAergic (and potentially catecholaminergic) signal transmission.

\section{References}

Badea TC, Nathans J (2004) Quantitative analysis of neuronal morphologies in the mouse retina visualized by using a genetically directed reporter. J Comp Neurol 480:331-351.
Ballesta J, Terenghi G, Thibault J, Polak JM (1984) Putative dopaminecontaining cells in the retina of seven species demonstrated by tyrosine hydroxylase immunocytochemistry. Neuroscience 12:1147-1156.

Bloomfield SA, Völgyi B (2007) Response properties of a unique subtype of wide-field amacrine cell in the rabbit retina. Vis Neurosci 24:459-469.

Bolte S, Cordelières FP (2006) A guided tour into subcellular colocalization analysis in light microscopy. J Microsc 224:213-232.

Contini M, Lin B, Kobayashi K, Okano H, Masland RH, Raviola E (2010) Synaptic input of ON-bipolar cells onto the dopaminergic neurons of the mouse retina. J Comp Neurol 518:2035-2050.

Cook PB, McReynolds JS (1998) Lateral inhibition in the inner retina is important for spatial tuning of ganglion cells. Nat Neurosci 1:714-719.

Dedek K, Breuninger T, de Sevilla Müller LP, Maxeiner S, Schultz K, JanssenBienhold U, Willecke K, Euler T, Weiler R (2009) A novel type of interplexiform amacrine cell in the mouse retina. Eur J Neurosci 30:217-228.

Demb JB (2008) Functional circuitry of visual adaptation in the retina. J Physiol 586:4377-4384.

Dumitrescu ON, Pucci FG, Wong KY, Berson DM (2009) Ectopic retinal ON bipolar cell synapses in the OFF inner plexiform layer: contacts with dopaminergic amacrine cells and melanopsin ganglion cells. J Comp Neurol 517:226-244.

Eggers ED, Lukasiewicz PD (2010) Interneuron circuits tune inhibition in retinal bipolar cells. J Neurophysiol 103:25-37.

Flores-Herr N, Protti DA, Wässle H (2001) Synaptic currents generating the inhibitory surround of ganglion cells in the mammalian retina. J Neurosci 21:4852-4863.

Freed MA, Pflug R, Kolb H, Nelson R (1996) ON-OFF amacrine cells in cat retina. J Comp Neurol 364:556-566.

Ghosh KK, Bujan S, Haverkamp S, Feigenspan A, Wässle H (2004) Types of bipolar cells in the mouse retina. J Comp Neurol 469:70-82.

Grimes WN, Zhang J, Graydon CW, Kachar B, Diamond JS (2010) Retinal parallel processors: more than 100 independent microcircuits operate within a single interneuron. Neuron 65:873-885.

Gustincich S, Feigenspan A, Wu DK, Koopman LJ, Raviola E (1997) Control of dopamine release in the retina: a transgenic approach to neural networks. Neuron 18:723-736.

Haverkamp S, Wässle H (2000) Immunocytochemical analysis of the mouse retina. J Comp Neurol 424:1-23.

Haverkamp S, Wässle H (2004) Characterization of an amacrine cell type of the mammalian retina immunoreactive for vesicular glutamate transporter 3. J Comp Neurol 468:251-263.

Haverkamp S, Ghosh KK, Hirano AA, Wässle H (2003) Immunocytochemical description of five bipolar cell types of the mouse retina. J Comp Neurol 455:463-476.

Haverkamp S, Müller U, Zeilhofer HU, Harvey RJ, Wässle H (2004) Diversity of glycine receptors in the mouse retina: localization of the alpha2 subunit. J Comp Neurol 477:399-411.

Haverkamp S, Specht D, Majumdar S, Zaidi NF, Brandstätter JH, Wasco W, Wässle H, Tom Dieck S (2008) Type 4 OFF cone bipolar cells of the mouse retina express calsenilin and contact cones as well as rods. J Comp Neurol 507:1087-1101.

Hoshi H, Liu WL, Massey SC, Mills SL (2009) ON inputs to the OFF layer: bipolar cells that break the stratification rules of the retina. J Neurosci 29:8875-8883.

Hsueh HA, Molnar A, Werblin FS (2008) Amacrine-to-amacrine cell inhibition in the rabbit retina. J Neurophysiol 100:2077-2088.

Ivanova E, Müller U, Wässle H (2006) Characterization of the glycinergic input to bipolar cells of the mouse retina. Eur J Neurosci 23:350-364.

Johnson J, Tian N, Caywood MS, Reimer RJ, Edwards RH, Copenhagen DR (2003) Vesicular neurotransmitter transporter expression in developing postnatal rodent retina: GABA and glycine precede glutamate. J Neurosci 23:518-529.

Lin B, Masland RH (2006) Populations of wide-field amacrine cells in the mouse retina. J Comp Neurol 499:797-809.

Lukasiewicz PD (2005) Synaptic mechanisms that shape visual signaling at the inner retina. Prog Brain Res 147:205-218.

Lyubarsky AL, Daniele LL, Pugh EN Jr (2004) From candelas to photoisomerizations in the mouse eye by rhodopsin bleaching in situ and the light-rearing dependence of the major components of the mouse ERG. Vision Res 44:3235-3251.

MacNeil MA, Masland RH (1998) Extreme diversity among amacrine cells: Implications for function. Neuron 20:971-982. 
Majumdar S, Wässle H, Jusuf PR, Haverkamp S (2008) Mirror-symmetrical populations of wide-field amacrine cells of the macaque monkey retina. J Comp Neurol 508:13-27.

Majumdar S, Weiss J, Wässle H (2009) Glycinergic input of widefield, displaced amacrine cells of the mouse retina. J Physiol 587:3831-3849.

Mariani AP (1991) Synaptic organization of type 2 catecholamine amacrine cells in the rhesus monkey retina. J Neurocytol 20:332-342.

Mariani AP, Hokoc JN (1988) Two types of tyrosine hydroxylaseimmunoreactive amacrine cell in the rhesus monkey retina. J Comp Neurol 276:81-91.

Mataruga A, Kremmer E, Müller F (2007) Type 3a and type 3b OFF cone bipolar cells provide for the alternative rod pathway in the mouse retina. J Comp Neurol 502:1123-1137.

Matsushita N, Okada H, Yasoshima Y, Takahashi K, Kiuchi K, Kobayashi K (2002) Dynamics of tyrosine hydroxylase promoter activity during midbrain dopaminergic neuron development. J Neurochem 82:295-304.

Menger N, Pow DV, Wässle H (1998) Glycinergic amacrine cells of the rat retina. J Comp Neurol 401:34-46.

Molnar A, Werblin F (2007) Inhibitory feedback shapes bipolar cell responses in the rabbit retina. J Neurophysiol 98:3423-3435.

Molnar A, Hsueh HA, Roska B, Werblin FS (2009) Crossover inhibition in the retina: circuitry that compensates for nonlinear rectifying synaptic transmission. J Comput Neurosci 27:569-590.

Oh SJ, Kim IB, Lee EJ, Kim KY, Kim HI, Chun MH (1999) Immunocytological localization of dopamine in the guinea pig retina. Cell Tissue Res 298:561-565.

Park DH, Teitelman G, Evinger MJ, Woo JI, Ruggiero DA, Albert VR, Baetge EE, Pickel VM, Reis DJ, Joh TH (1986) Phenylethanolamine $\mathrm{N}$-methyltransferase-containing neurons in rat retina: immunohistochemistry, immunochemistry, and molecular biology. J Neurosci 6:1108-1113.

Pérez De Sevilla Müller L, Shelley J, Weiler R (2007) Displaced amacrine cells of the mouse retina. J Comp Neurol 505:177-189.

Roska B, Werblin F (2001) Vertical interactions across ten parallel, stacked representations in the mammalian retina. Nature 410:583-587.

Schmitz F, Königstorfer A, Südhof TC (2000) RIBEYE, a component of syn- aptic ribbons: a protein's journey through evolution provides insight into synaptic ribbon function. Neuron 28:857-872.

Schwartz G, Berry MJ 2nd (2008) Sophisticated temporal pattern recognition in retinal ganglion cells. J Neurophysiol 99:1787-1798.

Solessio E, Vigh J, Cuenca N, Rapp K, Lasater EM (2002) Membrane properties of an unusual intrinsically oscillating, wide-field teleost retinal amacrine cell. J Physiol 544:831-847.

Stafford DK, Dacey DM (1997) Physiology of the A1 amacrine: a spiking, axon-bearing interneuron of the macaque monkey retina. Vis Neurosci 14:507-522.

Ueno S, Bracamontes J, Zorumski C, Weiss DS, Steinbach JH (1997) Bicuculline and gabazine are allosteric inhibitors of channel opening of the GABAA receptor. J Neurosci 17:625-634.

Versaux-Botteri C, Martin-Martinelli E, Nguyen-Legros J, Geffard M, Vigny A, Denoroy L (1986) Regional specialization of the rat retina: catecholamine-containing amacrine cell characterization and distribution. J Comp Neurol 243:422-433.

Völgyi B, Deans MR, Paul DL, Bloomfield SA (2004) Convergence and segregation of the multiple rod pathways in mammalian retina. J Neurosci 24:11182-11192.

Wässle H, Chun MH（1988） Dopaminergic and indoleamine-accumulating amacrine cells express GABA-like immunoreactivity in the cat retina. J Neurosci 8:3383-3394.

Wässle H, Puller C, Müller F, Haverkamp S (2009) Cone contacts, mosaics, and territories of bipolar cells in the mouse retina. J Neurosci 29:106-117.

Witkovsky P (2004) Dopamine and retinal function. Doc Ophthalmol 108:17-40

Zhang DQ, Stone JF, Zhou T, Ohta H, McMahon DG (2004) Characterization of genetically labeled catecholamine neurons in the mouse retina. Neuroreport 15:1761-1765.

Zhang DQ, Zhou TR, McMahon DG (2007) Functional heterogeneity of retinal dopaminergic neurons underlying their multiple roles in vision. J Neurosci 27:692-699.

Zhang DQ, Wong KY, Sollars PJ, Berson DM, Pickard GE, McMahon DG (2008) Intraretinal signaling by ganglion cell photoreceptors to dopaminergic amacrine neurons. Proc Natl Acad Sci U S A 105:14181-14186. 